\title{
Micro-sized erosions in a nanofilled composite after repeated acidic beverage exposures: consequences of clusters dislodgments
}

\author{
Nádia da Rocha SVIZERO'1, Adriana Regina Cruz Grando de GÓES², Tamires de Luccas BUENO², Vinicius DI \\ HIPÓLITO ${ }^{3}$, Linda WANG ${ }^{2}$, Paulo Henrique Perlatti D'ALPINO ${ }^{3}$
}

\begin{abstract}
1- Hospital for Rehabilitation of Craniofacial Anomalies (HRAC-USP), University of São Paulo, Bauru, SP, Brazil.
2- Department of Operative Dentistry, Endodontics and Dental Materials, Bauru School of Dentistry, University of São Paulo, Bauru, SP, Brazil.

3- Biomaterials Research Group, Universidade Anhanguera de São Paulo (UNIAN-SP), São Paulo, SP, Brazil.
\end{abstract}

Corresponding address: Nádia da Rocha Svizero - Hospital de Reabilitação de Anomalias Craniofaciais - Setor de Dentística - Universidade de São Paulo - Rua Silvio Marchione, 3-20 - Vila Universitária - 17012-900 - Bauru - SP - Brazil - Phone: +55 1432358180 - e-mail: nadiasvizero@hotmail.com

Submitted: November 22, 2013 - Modification: January 28, 2014 - Accepted: May 10, 2014

\section{ABSTRACT}

\begin{abstract}
bjective: To evaluate the hardness $(\mathrm{KHN})$, color stability $(\Delta \mathrm{E})$, and superficial micromorphology of two categories of composites after immersion in either distilled water or grape juice for up to 45 days. Material and Methods: Cylindrical specimens $(6 \mathrm{~mm}$ diameter $\times 2 \mathrm{~mm}$ thick) were obtained according to the factors: composite [Opallis (FGM) and Filtek Z350XT (3M ESPE)]; immersion solution (distilled water and grape juice); and evaluation time: $24 \mathrm{~h}$ and $7,14,21,28$, and 45 days. After photoactivation, the specimens were stored at $37^{\circ} \mathrm{C}$ for $24 \mathrm{~h}$. $\mathrm{KHN}(50 \mathrm{~g} / 15 \mathrm{~s})$ and $\Delta \mathrm{E}$ were then repeatedly assessed according to the immersion solutions. Data were analyzed (three-way ANOVA/Tukey's test). Scanning electron microscopy (SEM) topographic analysis was also performed. Results: In general, KHN of both composites reduced after $24 \mathrm{~h}$, irrespective of the immersion solution and time. A significantly lower KHN was noted for Opallis compared with Filtek Z350XT in all parameters. An increase in $\Delta \mathrm{E}$ over time was noted for both composites, irrespective of the immersion solution. Significantly higher $\Delta \mathrm{E}$ was noted for Filtek Z350XT immersed in grape juice compared with Opallis, regardless of the evaluation time. The grape juice caused significantly higher $\Delta \mathrm{E}$ compared with water in all periods. SEM analysis showed eroded areas for Filtek Z350XT but not for Opallis. Conclusions: The compositions and immersion solutions influence the composite hardness and the color stability. In spite of the higher hardness, the nanofilled composite is more susceptible to color change than the microhybrid when immersed in an acidic dyed solution.
\end{abstract}

Keywords: Composite resins. Color. Hardness. Time factor.

\section{INTRODUCTION}

Resin composites have been widely used in clinical practice to restore dental structures with excellence. Since their first introduction by Bowen in 1963, composites have been basically composed of organic matrix, fillers, and a silane agent that connects the filler and organic matrix ${ }^{12}$. Despite evolving technology, scientific and industrial efforts have mainly addressed improving properties related to the filler characteristics ${ }^{2,10,28}$. Once in the oral environment, the esthetic restorations are susceptible to staining, since the consumption of food and its fermentation produce dyed byproducts that can change the tooth surface even in a short period of time ${ }^{8}$. Composite discoloration can occur due to extrinsic or intrinsic factors. The main intrinsic factors are related to the modification in the resin matrix ${ }^{13}$, in the matrix/filler interface ${ }^{4}$, and incomplete curing of the material ${ }^{6}$. The presence of the photoinitiator system, especially camphorquinone ${ }^{6}$, can also significantly influence the color stability of composites. The affinity of the resin matrix for dyes is modulated by the degree of conversion of material, so when this proves insufficient, it tends to result in dye 
absorption ${ }^{18}$. The extrinsic discoloration may result from smoking pigments, poor oral hygiene, and especially the absorption of dyes from different foods and drinks ${ }^{30}$.

The organic matrixes and fillers also affect the surface polish and the susceptibility to extrinsic staining of bonded restorations ${ }^{25}$. Composites with smaller filler content by volume can absorb water in the matrix/filler interface ${ }^{30}$. This interface has high sensibility to sorption ${ }^{22}$. The absorbed water may cause the separation of the matrix/filler interface or hydrolytic degradation of the particles resulting in color change of the restorative material ${ }^{19,30}$. Thus, the hydrolytic degradation results from breakage of the chemical structure of the resin composite or softening through the plasticization action exerted by water ${ }^{27}$. Nanofilled composites were recently developed in order to offer optimized mechanical properties, and considering the increased demand for a universal restorative material, they were indicated for anterior and posterior teeth ${ }^{21}$. It is believed that the packing and distribution of fillers in these classifications of composites would improve their resistance to chemical challenges, preventing an earlier color change. Thus, the aim of this study was to evaluate the color stability of two resin composites (a microhybrid composite and a nanofilled composite) after immersion in a dye solution or distilled water for different periods of time. Drawing upon two hypotheses, this study attempts to investigate the effects of immersion protocols and several evaluation times on the Knoop hardness and color changes of two commercial resin composites. The hypotheses tested were as follows: (1) the immersion solutions affect the hardness of the composites, irrespective of the evaluation time; and (2) the color change will be altered as a function of the immersion protocol and evaluation time.

\section{MATERIAL AND METHODS}

\section{Experimental design}

In this in vitro study, the hardness and the color change evaluations were performed according to the factors: (1) composites, at two levels: microhybrid composite Opallis (shade EA2) and nanofilled composite Filtek Z350XT (shade A2E); (2) immersion solution at two levels: control (distilled water) and grape juice; and (3) evaluation time at five levels: 24 h, 7 days, 15 days, 30 days, 45 days. The characteristics of the resin composites selected are described in Figure 1. Twenty experimental groups were obtained among the combinations of the factors under study for each one of the evaluations performed.

\section{Specimen fabrication}

Materials were inserted into a Teflon mold (2 $\mathrm{mm}$ thick, $6 \mathrm{~mm}$ diameter) and photoactivated according to manufacturers' directions (20 s curing time). After insertion, a polyester strip was applied to the surface of the unpolymerized material and a microscope slide was pressed against the composite surface to adapt the material completely to the inner portion of the mold. In this way, flat top and bottom surfaces and similar composite volumes were obtained. The excess material was removed and the specimens were then photoactivated at the top surface. A quartz-tungsten-halogen (QTH) curing light was used to polymerize the specimens (Ivoclar Vivadent Astralis 3, Schann, Liechtenstein) with a power density of $600 \mathrm{~mW} / \mathrm{cm}^{2}$. Prior to testing and throughout the experiment, the power density was monitored using a handheld radiometer (Model 100, Demetron Research Corp., Danbury, CT, USA).

\section{Hardness test}

Cylindrical specimens were divided into 2 groups $(n=5)$, according to the immersion solution. After

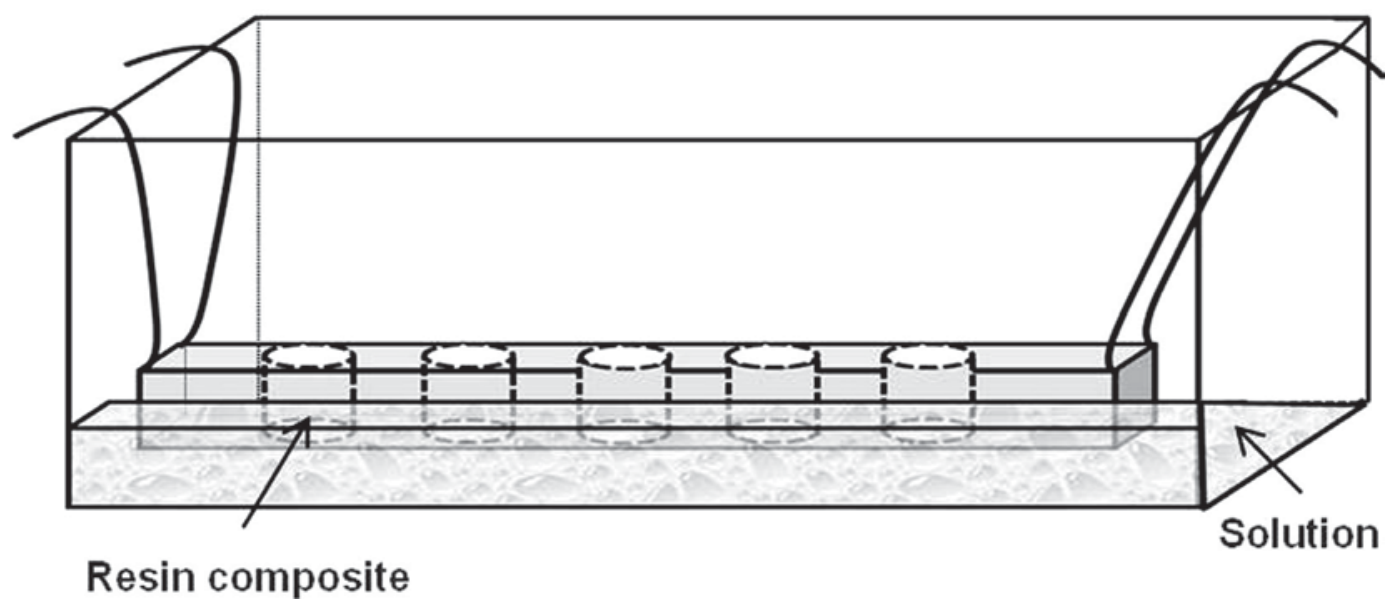

Figure 1- Schematic representation of the ethylene vinyl acetate (EVA) sheet rack used for the color change evaluation 
photoactivation, the specimens were removed from the molds and the top surface was identified with an indelible mark. A single operator prepared the specimens. The specimens were then stored in lightproof recipients for $24 \mathrm{~h}$. After storage, the specimens were placed in the testing table were stabilized with the same standardized acrylic matrix used during the polishing procedures. The microhardness test was performed in a digital Knoop hardness-measuring instrument under load (Shimadzu HMV-M Microhardness Tester; Newage Testing instruments Inc., Southampton, PA, USA). Six randomized indentations (3 on both the top and bottom surfaces) were made with a $50 \mathrm{~g}$ load for $15 \mathrm{~s}$, with a dwell time of $15 \mathrm{~s}$. For randomization, specimens were arbitrarily rotated before indentations. The specimens were tested by a single operator throughout the evaluation times.

After the initial hardness evaluation, the specimens of each material were distributed in two groups $(n=5)$, according to the immersion solution protocols: distilled water and grape juice (Salton, Bento Gonçalves, RS, Brazil - pH 2.8). After the initial hardness evaluation (irradiated top surface), the specimens were fixed in an ethylene vinyl acetate (EVA) sheet rack (Figure 1) and stabilized with colorless solid paraffin in order to maintain only the irradiated surfaces exposed to the immersion solutions. The specimens of both resin composites $(n=5)$ were daily submitted to two immersion cycles of $10 \mathrm{~min}$ in $100 \mathrm{~mL}$ of grape juice, which was renewed in all of the immersion cycles. Care was taken in order to guarantee that the $\mathrm{pH}$ value of the grape juice was the same previously the immersion time. In the remaining time, the specimens were washed and immersed in distilled water, which was also renewed daily. The remaining specimens $(n=5)$ were immersed in distilled water throughout the experimental period (control group), which was renewed daily as well. The top surface of the specimens (irradiated surface) was subjected to Knoop hardness assessment according to the evaluation times of 24 h, 7 days, 14 days, 28 days, and 45 days.

\section{Color-change evaluation}

In the same way, the cylindrical composite specimens were divided into 2 groups $(n=5)$, according to the immersion solution. The irradiated surfaces were polished with sequential abrasive discs (3M ESPE Sof-Lex, Extra-thin contouring and polishing discs, St. Paul, MN, USA) and mounted in a slow-speed handpiece, according to the protocol, as follows: sanding with a medium-granulation sandpaper (2382M) for $10 \mathrm{~s}$, then with a finegranulation sandpaper (2382F) for $10 \mathrm{~s}$, and finally with an extra-fine-granulation sandpaper (2382SF) for $10 \mathrm{~s}$. The specimens were firmly positioned in a standardized acrylic matrix during the polishing procedures. The specimens were then washed in distilled water for $10 \mathrm{~s}$, dried with an absorbent paper and stored in the dark for $24 \mathrm{~h}$ before the initial color readings.

The CIEL*a*b* system was used to evaluate the color change. This methodology is based on an analysis with a spectrophotometer with threedimensional distribution, following pre-defined standards: L* $a^{*} b^{*}$ defined by the Commission Internationale de L'Eclairage (CIE, 1976). L* represents the white and black shift which white has a positive value and black has a negative value; a* represents the red and green shift for which red has a positive value and green has a negative value; $b$ * represents the yellow and blue shift for which yellow has a positive value and blue has a negative value. These values were calculated according to the formula:

\section{$\Delta \mathrm{E}=\left[(\Delta \mathrm{L})^{2}+(\Delta \mathrm{a})^{2}+(\Delta \mathrm{b})^{2}\right] 1 / 2$}

All color readings were taken only on the top surface of the specimens with a spectrophotometer (Vita Easyshade, Vita Zahnfabrik, Bad Säckingen, Baden-Württemberg, Germany). After the initial color measurements, the specimens were fixed in an ethylene vinyl acetate (EVA) sheet rack (Figure

\begin{tabular}{|c|c|c|c|}
\hline Material & Organic matrix * & Fillers * & Weight (W) / Volume (V)* \\
\hline $\begin{array}{c}\text { Opallis (FGM Produtos } \\
\text { Odontológicos LTDA, } \\
\text { Joinville SC, Brazil) }\end{array}$ & $\begin{array}{c}\text { Bis-GMA, UDMA, TEGDMA, } \\
\text { and Bis-EMA }\end{array}$ & $\begin{array}{c}\text { Silanized barium-aluminum- } \\
\text { silicate glass, pigments, and } \\
\text { silica }(40 \mathrm{~nm} \text { to } 2.0 \mu \mathrm{m}- \\
\text { average } 0.5 \mu \mathrm{m})\end{array}$ & W: $78.5 \%$ V: 58 \% \\
\hline $\begin{array}{c}\text { Filtek Z350XT (3M ESPE, } \\
\text { St. Paul, MN, USA) }\end{array}$ & $\begin{array}{c}\text { Bis-GMA, UDMA, TEGDMA, } \\
\text { PEGDMA, and Bis-EMA }\end{array}$ & $\begin{array}{c}\text { Silica }(20 \mathrm{~nm}) ; \text { Zirconia }(4- \\
11 \mathrm{~nm}) ; \text { Clusters of particles } \\
\text { aggregate of silica/zirconia } \\
(20 \mathrm{~nm} \text { and } 4-11 \mathrm{~nm})\end{array}$ & W: $78.5 \% \mathrm{~V}: 63.3 \%$ \\
\hline
\end{tabular}

*Manufacturer's information

Bis-GMA - Bis-phenol A di-Glycidyl methacrylate; Bis-EMA - Bis-phenol A di-Glycidyl ethoxylate methacrylate; TEGDMA Triethylene glycol dimethacrylate; UDMA - Urethane dimethacrylate; PEGDMA - Polyethylene glycol dimethacrylate

Figure 2- Composition of evaluated resin composites 
2) and stabilized with colorless paraffin in order to maintain only the irradiated surfaces exposed to the immersion solutions. Subsequently, five specimens of both resin composites were daily submitted to two 10-min immersion cycles in 100 $\mathrm{mL}$ of the grape juice, which was renewed in all of the cycles. In the remaining time, the specimens were washed and immersed in distilled water, which was renewed daily. The remaining specimens $(n=5)$ were immersed in distilled water throughout the experimental period (control group), which was renewed daily as well. The color changes were analyzed weekly according to the experimental design $(7,14,21,28$ and 45 days). Before each color measurement, the specimens were carefully dried with an absorbent paper.

\section{Statistical analysis}

The assumptions of equality of variances and normal distribution of errors were checked by the Kolmogorov-Smirnov and Bartlett tests, respectively. As a normal distribution was satisfied, the means of hardness and DE were compared by means of a three-way ANOVA, followed by a multiple comparison test performed with the Tukey test, at a pre-set alpha of $1 \%$.

\section{SEM observation}

In order to characterize the topographic aspect of both resin composites after 45 days of storage, three specimens of each experimental group used for the color change evaluation were evaluated under scanning electron microscopy
(SEM). For comparative reasons, control groups (non-stored specimens) were also evaluated. In addition, representative images of selected regions of both resin composites were obtained to characterize the morphological aspects of the filler particles and the distribution/packing. For this, three additional specimens of non-storage resin composites were immersed into acetone p.a. (Ref. 32201, Sigma-Aldrich, St. Louis, MO, USA) for 3 days in order to dissolve the organic matrix. All of the specimens obtained, regardless of the preliminary process, were then dehydrated over silica gel for $2 \mathrm{~h}$, sputter-coated ( $40 \mathrm{~mA}$ for 120 s) with gold/palladium (SCD 050, Balzers, Schaan, Liechtenstein), and then investigated by means of SEM (JSM 5600LV, JEOL, Tokyo, Japan), under secondary electron mode, operating at $15-25 \mathrm{kV}$.

\section{RESULTS}

The means and standard deviations of KHN are presented in Table 1. The factors of "composite", "immersion solution" and "storage time" were statistically significant $(p<0.01)$. Interactions between the factors of "composite" and "immersion solution"; "composite" and "evaluation time"; and "composite", "immersion solution" and "evaluation time" were all significant $(p<0.01)$. No significance was noted for the interaction between the factors of "immersion solution" and "evaluation time" $(p=0.45)$. Opallis showed lower KHN values than Filtek Z350XT whether immersed in water or in grape juice in all of the evaluated times. No

Table 1- Means (standard deviations) of hardness (KHN) of the tested resin composites as a function of the immersion solutions and evaluation time

\begin{tabular}{|c|c|c|c|c|c|c|}
\hline \multirow{2}{*}{$\begin{array}{c}\text { Resin } \\
\text { composite }\end{array}$} & \multirow{2}{*}{$\begin{array}{l}\text { Immersion } \\
\text { solutions }\end{array}$} & \multicolumn{5}{|c|}{ Evaluation Time } \\
\hline & & $24 \mathrm{~h}$ & 7 days & 14 days & 28 days & 45 days \\
\hline & Distilled water & $53.3^{\mathrm{aA}} \$$ & $43.3^{\mathrm{aA}}$ & $43.2^{\mathrm{aA}^{*}}$ & $40.4^{\mathrm{aA}}$ & $38.6^{\mathrm{aA}^{*}}$ \\
\hline \multirow[t]{4}{*}{ Opallis } & & (2.9) & $(2.1)$ & $(1.8)$ & (1.3) & $(1.4)$ \\
\hline & Grape juice & $52.1^{\mathrm{AA}} \$$ & $45.9^{a A^{*}}$ & $41.9^{\mathrm{aA}^{*}}$ & $40.2^{\mathrm{aA}^{*}}$ & $38.0^{a A^{*}}$ \\
\hline & & (1.7) & $(1.7)$ & (1.4) & (1.6) & $(0.9)$ \\
\hline & Distilled water & $68.8^{\mathrm{BA}} \$$ & $58.6^{\mathrm{bA}}$ & $52.2^{\mathrm{bA}^{*}}$ & $51.2^{\mathrm{bA}^{*}}$ & $50.1^{\mathrm{bA}^{*}}$ \\
\hline \multirow[t]{3}{*}{ Filtek Z350XT } & & (2.6) & $(1.1)$ & (1.5) & (1.3) & $(1.0)$ \\
\hline & Grape juice & $67.2^{\mathrm{bA}} \$$ & $54.2^{\mathrm{bB}}$ & $51.9^{\mathrm{bA}^{*}}$ & $48.5^{\mathrm{bA}^{*}}$ & $45.6^{\mathrm{bB}}$ \\
\hline & & (1.1) & $(1.3)$ & (1.5) & (1.1) & $(1.3)$ \\
\hline
\end{tabular}

$\mathrm{n}=5$

Different lowercase letters for rows: significant $(p<0.01)$, comparing the KHN means of both composites in the same immersion solution and same evaluation time.

Different uppercase letters for columns: significant $(p<0.01)$, comparing the KHN means of the same composite in both immersion solutions and same evaluation time.

Different symbols ( ${ }^{*}$ and $\$$ ): significant $(p<0.01)$, comparing the KHN means at the different evaluation times (columns) for the same composite and same immersion solution. 
significance in the KHN means of the composite Opallis was noted when the immersion protocols were compared, for all of the evaluation times tested $(p>0.01)$. Conversely, for the composite Filtek Z350XT significantly higher means were noted when immersed in water than in grape juice for the times of 7 and 45 days. Regarding the immersion solution and resin composite, the results indicate that the hardness means of both composites tested were significantly reduced after $24 \mathrm{~h}$.

The means and standard deviations of $\Delta \mathrm{E}$ are presented in Table 2. The triple interaction of the factors of "composite", "immersion solution", and "evaluation time" was significant $(p<0.01)$. The interactions between "composite" $x$ "immersion solution", "composite" x "evaluation time", and "immersion solution" $x$ "evaluation time" were also statistically significant $(p<0.01)$. No significance was noted between the $\Delta \mathrm{E}$ means for both composites when immersed in water $(p>0.01)$. On the other hand, a significant increase in the $\Delta \mathrm{E}$ means was noted for Filtek Z350XT for all of the evaluation times. For the composite Opallis, a significant increase in the $\Delta \mathrm{E}$ was only noted after 45 days for both immersion protocols. Conversely, when the $\Delta \mathrm{E}$ means of the immersion protocols were compared, significance was noted in all of the evaluation times for Filtek Z350XT. Regarding the evaluation time, a significant increase in the $\Delta \mathrm{E}$ means of Opallis was noted after 21 days, irrespective to the immersion solution. For the composite Filtek Z350XT, a significant increase in the $\Delta \mathrm{E}$ means was only noted after 45 days when immersed in distilled water whereas a significant increase was noted after 14 days of immersion in grape juice.

The morphologic characterization of the composites tested is illustrated in the Figure 3 . The topographic aspect of the composite Opallis after immersion in both water and grape juice exhibited no evidence of topographic changes in comparison to that observed in the control group (non-storage specimens) (Figure 3A, Figure 3A1, and Figure 3A2). For the composite Filtek Z350XT, a similar topographic aspect was observed when the non-stored and water-stored specimens were compared (Figures 3B and B1); however, when stored in grape juice, the topographic micrographic images exhibited superficial irregularities in which micro-sized eroded areas were identified (Figures 3B2 and B2'), due to filler dislodgement and/or organic matrix degradation. The characterization of the inorganic fillers of the resin composites showed that the composite Opallis presented irregular micrometric-sized fillers (Figure 3A3), while Filtek Z350XT presented nanometric fillers arranged in clusters (Figure 3B3').

Table 2- Means (standard deviations) of color stability $(\Delta \mathrm{E})$ of the composites with regard to the immersion solution and evaluation time

\begin{tabular}{|c|c|c|c|c|c|c|}
\hline \multirow{3}{*}{$\begin{array}{c}\text { Resin } \\
\text { Composite }\end{array}$} & \multirow{2}{*}{$\begin{array}{c}\text { Immersion } \\
\text { Solutions }\end{array}$} & \multicolumn{5}{|c|}{ Evaluation Time } \\
\hline & & 7 days & 14 days & 21 days & 28 days & 45 days \\
\hline & $\begin{array}{l}\text { Distilled } \\
\text { water }\end{array}$ & $1.78^{\mathrm{aA}}$ & $1.96^{\mathrm{aA}^{*}}$ & $2.65^{\mathrm{aA}} \$$ & $2.87^{\mathrm{aA}} \$$ & $3.20^{\mathrm{aA}} \$$ \\
\hline \multirow[t]{4}{*}{ Opallis } & & $(0.09)$ & $(0.08)$ & $(0.42)$ & $(0.33)$ & $(0.23)$ \\
\hline & Grape juice & $1.38^{\mathrm{a} \mathrm{A}^{*}}$ & $1.72^{\mathrm{aA}^{*}}$ & $2.78^{\mathrm{aA}} \$$ & $2.99^{\mathrm{aA}} \$$ & $5.60^{\mathrm{aB}} \$$ \\
\hline & & $(0.12)$ & $(0.19)$ & $(0.21)$ & $(0.15)$ & $(0.35)$ \\
\hline & $\begin{array}{l}\text { Distilled } \\
\text { water }\end{array}$ & $1.59^{\mathrm{aA}}$ & $1.66^{\mathrm{aA}}$ & $1.87^{\mathrm{aA}^{*}}$ & $1.88^{\mathrm{aA}^{*}}$ & $2.25^{\mathrm{aA}} \$$ \\
\hline \multirow{3}{*}{$\begin{array}{c}\text { Filtek } \\
\text { Z350XT }\end{array}$} & & $(0.14)$ & $(0.18)$ & $(0.08)$ & $(0.07)$ & $(0.19)$ \\
\hline & Grape juice & $4.29^{\mathrm{bB}}$ & $6.67^{\mathrm{bB}} \$$ & $6.84^{\mathrm{bB}} \$$ & $7.07^{\mathrm{bB}} \$$ & $9.69^{\mathrm{bB}} \$$ \\
\hline & & $(0.35)$ & $(0.27)$ & $(0.32)$ & $(0.25)$ & $(0.37)$ \\
\hline
\end{tabular}

$\mathrm{n}=5$

Different lowercase letters for rows: significant $(p<0.01)$, comparing the $\Delta E$ means of both composites in the same immersion solution and same evaluation time.

Different uppercase letters for columns: significant $(p<0.01)$, comparing the $\Delta E$ means of the same composite in both immersion solutions and same evaluation time.

Different symbols ( ${ }^{*}$ and $\$$ ): significant $(p<0.01)$, comparing the $\Delta E$ means at the different evaluation times (columns) for the same composite and same immersion solution $(p<0.01)$. 

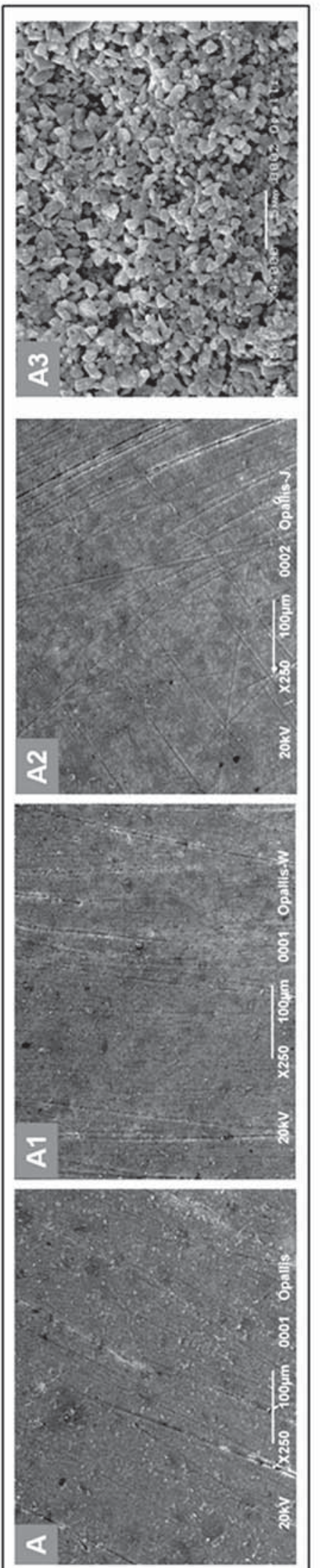

$\frac{\text { 을 }}{\overline{\bar{N}}}$
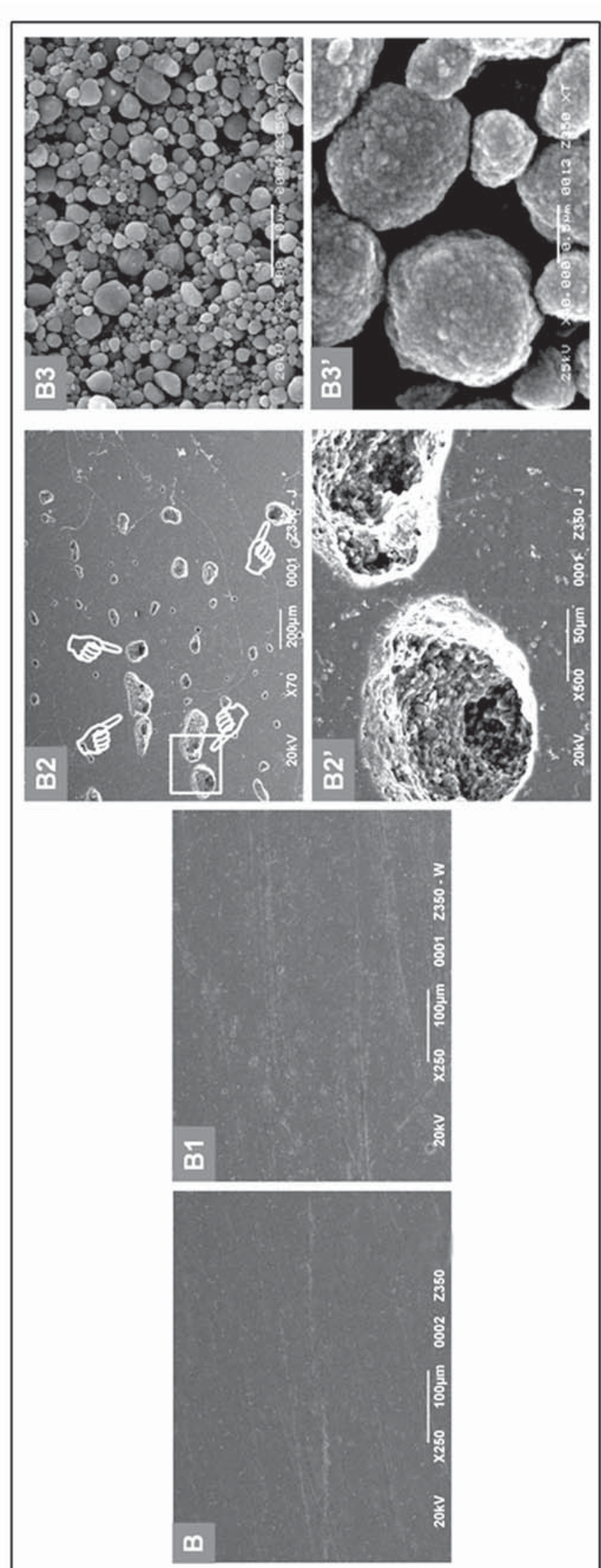

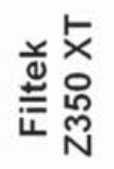

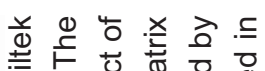

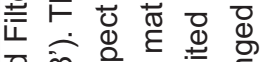

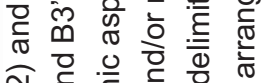

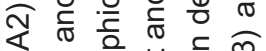

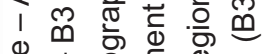

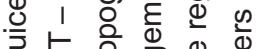

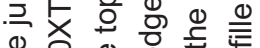

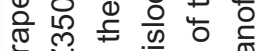
$\bar{N} \mathfrak{\omega}$

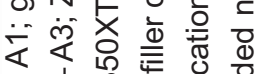
立金

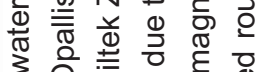

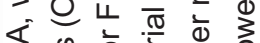

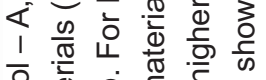

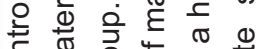
엉 है 임

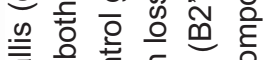
元

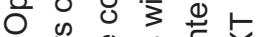

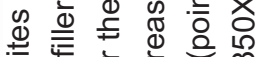
क है 产

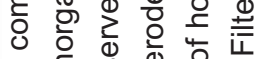
$₫$ 잉 t。

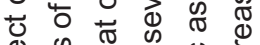

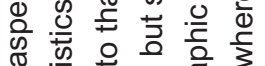

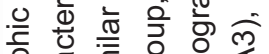
음 항 응 0

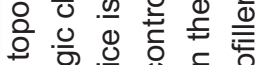
응 응 0.

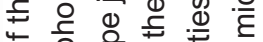

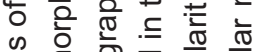

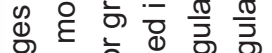
ॠ

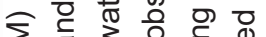

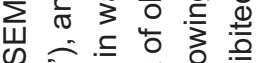

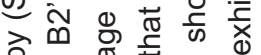

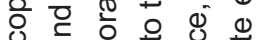

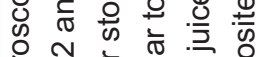

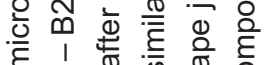
ह 100 क क 흘 를

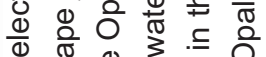

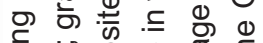
范。 क 1 है 像 0 \%

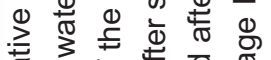

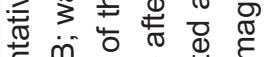
ब ه

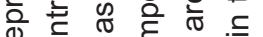

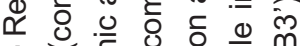
mं 등

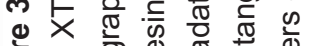

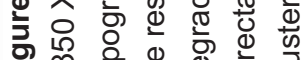

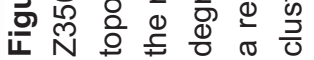




\section{DISCUSSION}

The first hypothesis, which anticipated that the immersion solutions affect the hardness of the composites, irrespective of the evaluation time, was accepted. It was found that the hardness of both composites tested was significantly reduced after $24 \mathrm{~h}$, irrespective of the immersion protocol. In addition, the hardness means were mainly influenced by material type. When the composites were compared, Opallis showed lower KHN values than Filtek Z350XT for all of the evaluated times, irrespective of the immersion protocol (Table 1 ). Explanations of the difference in the hardness means between the composites concern the filler concentration and type. Opallis composite is filled with a combination of silica fillers and radiopaque barium-aluminum-silicate glass, classified as a microhybrid composite. The concentration of filler particles in this composite is $78.5 \%$ by weight. Although the same concentration by weight was found for Filtek Z350XT, the fillers are composed of zirconia/silica, classified as a nanofilled composite. For comparative reasons, the KHN of glass is 530 , while the KHN of zirconia is $1,160^{24}$. Variables such as size, shape, distribution, and also content per volume/weight of the filler particles in the matrix have been claimed to influence the mechanical strength, hardness, and modulus of elasticity of composites $7,8,24$.

The second hypothesis, which anticipated that the color change would be altered as a function of the immersion protocols and evaluation times, was also accepted. A significant difference in $\Delta \mathrm{E}$ was noted for all of the evaluation times when the results of Filtek Z350XT in distilled water were compared to those of grape juice (Table 2). On the other hand, a significant increase in the $\Delta \mathrm{E}$ was only noted after 45 days for the composite Opallis in both immersion protocols. It could be argued that the type of particles in the resin composites tested could also be related to the results found, as the more radiopaque glasses contained in the microhybrid composite Opallis present greater dissolution in water. Radiopacity of composites usually results from the incorporation of elements of relatively high atomic number, such as barium and strontium, into the $\mathrm{SiO}_{2}$-based filler particles ${ }^{16,29}$. Radiopaque fillers contain at least one radiopaque oxide component, such as $\mathrm{BaO}, \mathrm{ZrO}_{2}$, or $\mathrm{Yb}_{2} \mathrm{O}_{3}$ at varying concentrations ${ }^{26}$. In a wet condition, the initiation of the crack/ flaw is then facilitated, requiring little effort, and the adhesion of the particles to the matrix can be destroyed by hydrolysis ${ }^{5}$. Although barium is the strongest radiopacifier for $\mathrm{SiO}_{2}$ glass, barium ions, once leached out into the water (or oral fluid), are potentially hazardous to the oral soft tissues $^{23}$. If the material is heterogeneous and anisotropic as almost all dental materials are, several sizes of defects are present as well. This potential deterioration of the glass is one of the reasons why it is so important to form an organic layer of silane molecules on the surface of the filler to protect it from the environment. On the other hand, it has been found that the silane treatment remains for at least 6 months, even when specimens are stored in adverse conditions in distilled water ${ }^{22}$. This would lead to increased $\Delta \mathrm{E}$ for Opallis over time. Conversely, a significant increase in the $\Delta \mathrm{E}$ was only noted after 45 days when both the immersion protocols were compared, whereas significance was noted for Filtek Z350XT in all of the evaluation times. In a previous study ${ }^{3}$, it was also demonstrated that the nanofilled composite Filtek Z350XT presents both an amorphous as well as a crystalline phase that are affected by a simplified aging protocol and that this fact may affect clinically relevant parameters such as mechanical/physical properties; fracture toughness, polymer conversion, strength, among others. These results indicate that Filtek Z350XT would be less clinically stable in comparison to other methacrylate-based composites. Clinically, color alterations in composite restorations are visually observed when the $\Delta \mathrm{E}$ is higher than $3.3^{6,19}$. In the present study, $\Delta \mathrm{E}>3.3$ was noted for Opallis only after 45 days of immersion in the grape juice, whereas for Filtek Z350XT at the first reading (after 7 days) a $\Delta E>3.3$ was noted for the same immersion media. Conversely, no clinically noticeable alterations would be noted for both resin composites when immersed in water, irrespective of the evaluation time (up to 45 days).

The topographic analysis demonstrated that eroded areas were observed for the composite Filtek Z350XT in the specimens after 45 days of immersion (Figure 3). Filtek Z350XT exhibited a distinctive and unique erosive pattern in which the agglomerated nano-sized particles were dislodged due to matrix degradation. On the other hand, no evidence of eroded areas was seen for the composite Opallis. This explains why the nanofilled composite presented increased $\Delta \mathrm{E}$. The explanations of the results obtained for Filtek Z350XT rely on the fact that this composite is constituted exclusively by silanized nanometricsized silica particles ( $20 \mathrm{~nm}$ ) and clusters of Si/Zr. Small filler particles expose a higher surface area to be coated by silane, making the silanization process more critical ${ }^{15}$ and increasing the chances of an interfacial failure ${ }^{14}$. It has been reported that a variety of chemical and physical processes at the interface matrix-filler interfere with the structure and function of polymeric materials ${ }^{17}$. The silane treatment of the filler provides a resin- 
to-filler bonding and has been shown to enhance the mechanical stability of the filler-matrix interface and increase the strength and hardness of composite resins ${ }^{20}$. It has been also claimed that the nanoclusters may provide a reinforcing mechanism and that the silane infiltration within the intimacy of the nanoclusters modifies the response to loading stresses, thus providing an improved clinical performance ${ }^{1}$. Nanoclusters has been also advocated to be useful for improving the wear resistance and for reducing the possibility of restoration resistance to fracture as the silane would fill the voids and gaps commonly observed in micro-hybrid composites ${ }^{1}$. Another possible explanation of the higher $\Delta \mathrm{E}$ seen for Filtek Z350XT could be the weak bonding between the particles and the resin matrix. As long as the eroded areas occurred throughout the evaluation times, the entrance of colored pigments contained in the grape juice was certainly possible after 14 days, at which point significant color change had occurred in comparison to the initial reading. The filler treatment and presence of interspacing caused by poor silanization process can affect the surface energy of the fillers, as any of those are considered defects to the material and concentrate stress.

This study demonstrated that, despite the similarity in terms of filler packing, the organic matrix and the filler types found in the compositions of composites tested influenced the results of hardness and color stability when immersed in different storage media over time. It is important to mention that the nanofilled composite was more influenced by immersion in the acidic dyed solution than the microhybrid composite. Moreover, in the present study, the nanofilled composite presented a higher decrease in hardness, which was more evident when immersed in the acidic dyed solution. Improvements, on the other hand, are necessary to improve the color stability of the nanofilled composite, especially in terms of the effectiveness and integrity of the silanization process, considering that the smaller the filler particles, the higher the surface area to be coated by silane, making the silanization process more critical. This is a critical clinical issue in esthetic dentistry and has to be further substantiated by evaluating the longevity of the restorations. Extrapolations to clinically support and validate the results using different categories of composites need to be done with caution since future studies are required.

\section{CONCLUSIONS}

Within the limitations of the present study, it can be concluded that:

The hardness and color stability results are dependent of the material;

Hardness and color stability of both composites progressively decrease as a function of time;

The nanofilled composite Filtek Z350XT presents higher hardness in comparison with the microhybrid Opallis, irrespective of the immersion protocol and evaluation times;

The nanofilled composite Filtek Z350XT is more susceptible to color changes and decrease in hardness when immersed in an acidic dyed solution, irrespective of the immersion time.

\section{ACKNOWLEDGEMENTS}

This study was partially supported by grants from CNPq 479744/2010-6 and 163102/2011-2 (P.I. Paulo H. P. D'Alpino), Brazil. The authors are grateful to Dr. Leonardo Fernandes da Cunha for the technical support on color-change analysis.

\section{REFERENCES}

1- Curtis AR, Palin WM, Fleming GJ, Shortall AC, Marquis PM. The mechanical properties of nanofilled resin-based composites: the impact of dry and wet cyclic pre-loading on bi-axial flexure strength. Dent Mater. 2009;25:188-97.

2- D'Alpino PH, Bechtold J, Santos PJ, Alonso RC, Di Hipolito $\mathrm{V}$, Silikas N, et al. Methacrylate- and silorane-based composite restorations: hardness, depth of cure and interfacial gap formation as a function of the energy dose. Dent Mater. 2011;27:1162-9.

3- D'Alpino PH, Vismara MV, Gonzalez AH, Graeff CF. Free radical entrapment and crystallinity of resin composites after accelerated aging as a function of the expiration date. J Mech Behav Biomed Mater. 2014;36C:82-9.

4- Güler AU, Güler E, Yücel AC, Ertaş E. Effects of polishing procedures on color stability of composite resins. J Appl Oral Sci. 2009;17:108-12.

5- Han L, Okamoto A, Fukushima M, Okiji T. Evaluation of physical properties and surface degradation of self-adhesive resin cements. Dent Mater J. 2007;26:906-14.

6- Janda R, Roulet JF, Latta M, Steffin G, Rüttermann S. Color stability of resin-based filling materials after aging when cured with plasma or halogen light. Eur J Oral Sci. 2005;113:251-7.

7- Lepri CP, Palma-Dibb RG. Surface roughness and color change of a composite: Influence of beverages and brushing. Dent Mater J. 2012;31:689-96.

8- Manhart J, Kunzelmann KH, Chen HY, Hickel R. Mechanical properties and wear behavior of light-cured packable composite resins. Dent Mater. 2000;16:33-40.

9- Oberholzer TG, Grobler SR, Pameijer $\mathrm{CH}$, Hudson AP. The effects of light intensity and method of exposure on the hardness of four light-cured dental restorative materials. Int Dent J. 2003; 53:211-5.

10- Oliveira GU, Mondelli RF, Charantola Rodrigues M, Franco EB, Ishikiriama SK, Wang L. Impact of filler size and distribution on roughness and wear of composite resin after simulated toothbrushing. J Appl Oral Sci. 2012;20:510-6.

11- Peris AR, Mitsui FH, Amaral CM, Ambrosano GM, Pimenta LA. The effect of composite type on microhardness when using quartztungsten-halogen (qth) or led lights. Oper Dent. 2005;30:649-54. 12- Polydorou $O$, Trittler R, Hellwig $E$, Kümmerer K. Elution of monomers from two conventional dental composite materials. Dent Mater. 2007;23:1535-41. 
13- Reis AF, Giannini M, Lovadino JR, Ambrosano GM. Effects of various finishing systems on the surface roughness and staining susceptibility of packable composite resins. Dent Mater. 2003;19:12-8.

14- Rodrigues Junior SA, Zanchi CH, Carvalho RV, Demarco FF. Flexural strength and modulus of elasticity of different types of resin-based composites. Braz Oral Res. 2007;21:16-21.

15- Sabbagh J, Ryelandt L, Bachérius L, Biebuyck JJ, Vreven J, Lambrechts $P$, et al. Characterization of the inorganic fraction of resin composites. J Oral Rehabil. 2004;31:1090-101.

16- Sabbagh J, Vreven J, Leloup G. Radiopacity of resin-based materials measured in film radiographs and storage phosphor plate (Digora). Oper Dent. 2004;29:677-84.

17- Santos C, Clarke RL, Braden M, Guitian F, Davy KW. Water absorption characteristics of dental composites incorporating hydroxyapatite filler. Biomaterials. 2002;23:1897-904.

18- Satou N, Khan AM, Matsumae I, Satou J, Shintani H. In vitro color change of composite-based resins. Dent Mater. 1989;5:3847.

19- Schulze KA, Marshall SJ, Gansky SA, Marshall GW. Color stability and hardness in dental composites after accelerated aging. Dent Mater. 2003;19:612-9.

20- Shajii L, Santerre JP. Effect of filler content on the profile of released biodegradation products in micro-filled bis-GMA/TEGDMA dental composite resins. Biomaterials. 1999;20:1897-908.

21- Silva EM, Almeida GS, Poskus LT, Guimarães JG. Relationship between the degree of conversion, solubility and salivary sorption of a hybrid and a nanofilled resin composite. J Appl Oral Sci. 2008;16:161-6.
22- Söderholm KJ. Degradation of glass filler in experimental composites. J Dent Res. 1981;60:1867-75.

23- Söderholm KJ, Yang MC, Garcea I. Filler particle leachability of experimental dental composites. Eur ] Oral Sci. 2000;108:555-60. 24- Ted Pella, Inc. Hardness tables: Mohs hardness scale [online]. 2013 Dec. 10. [cited 2013 Nov 22]. Available from: http://www. tedpella.com/company_html/hardness.htm.

25- Topcu FT, Sahinkesen G, Yamanel K, Erdemir U, Oktay EA, Ersahan S. Influence of different drinks on the colour stability of dental resin composites. Eur J Dent. 2009;3:50-6.

26- Toyooka H, Taira M, Wakasa K, Yamaki M, Fujita M, Wada T. Radiopacity of 12 visible-light-cured dental composite resins. J Oral Rehabil. 1993;20:615-22.

27- Vouvoudi EC, Sideridou ID. Effect of food/oral-simulating liquids on dynamic mechanical thermal properties of dental nanohybrid light-cured resin composites. Dent Mater. 2013;29:842-50.

28- Wang L, Garcia FC, Amarante de Araújo P, Franco EB, Mondelli RF. Wear resistance of packable resin composites after simulated toothbrushing test. J Esthet Restor Dent. 2004;16:303-15.

29- Watts DC. Radiopacity vs. composition of some barium and strontium glass composites. J Dent. 1987;15:38-43.

30- Yazici AR, Celik C, Dayangaç B, Ozgünaltay G. The effect of curing units and staining solutions on the color stability of resin composites. Oper Dent. 2007;32:616-22. 